\title{
Stage 0 Uterine Corpus Cancer AJCC v7
}

National Cancer Institute

\section{Source}

National Cancer Institute. Stage O Uterine Corpus Cancer A/CC V7. NCI Thesaurus. Code C89632.

Stage 0 includes: T is, N0, MO. T is: Carcinoma in situ. N0: No regional lymph node metastasis. M0: No distant metastasis. This staging applies to carcinomas and carcinosarcomas. FIGO no longer includes Stage 0 (T is). (AJCC 7th ed.) 